\title{
A Weighting Grade-Based Optimization Method for Determining Refill Friction Stir Spot Welding Process Parameters
}

\author{
Rafał Kluz, Andrzej Kubit, Tomasz Trzepiecinski (D), Koen Faes, and Wojciech Bochnowski
}

(Submitted March 1, 2019; in revised form August 11, 2019; published online October 9, 2019)

\begin{abstract}
The welding process used in fabricating thin-walled structures by refill friction stir spot welding (RFSSW) should be characterized by a high strength of welds and high process repeatability which is demonstrated by a small dispersion of the load capacity of the joints. The present work is designed to optimize RFSSW process parameters for 7075-T6 Alclad aluminum alloy sheets used to fabricate aircraft structures. The optimization was performed by scalarization of the objective function using the weighting grades method. The study considers the effect of process parameters, i.e., tool plunge depth, duration of welding, tool rotational speed, on the tensile/shear strength of the joints, and dispersion of the load capacity. It was found that it was possible to choose the optimal welding parameters taking into account maximization of the load capacity and minimization of the dispersion of the joint strength via a best compromise between the tool rotational speed ensuring adequate plasticization of the base material and the duration of welding ensuring that a fine-grained joint microstructure is obtained.
\end{abstract}

Keywords aluminum alloy, friction stir spot welding, optimization, welding

\section{Introduction}

Friction stir welding is a solid-state joining technique that is finding greater use in aircraft applications for manufacturing thin-walled aircraft components, especially stiffened panels. The FSW process is capable of welding some previously unweldable precipitation-strengthened aluminum alloy sheets. In a classical FSW process, a rotating cylindrical tool composed of a probe and a shoulder is plunged into the materials to be joined. Mechanical deformation of the materials is possible via the heat generated through friction (Ref 1, 2). FSW joints have higher strengths than riveted joints and much lower residual stresses than a typical fusion welded joint, like resistance spot welding (RSW) (Ref 3).

Refill friction stir spot welding (RFSSW) is a modern solidstate friction welding process which was developed by Helmholtz-Zentrum Geesthacht (Ref 4) for welding two or more similar or dissimilar sheets in a lap configuration. RFSSW is a solid-state joining technology which connects two similar or dissimilar materials together with minimal heat input or

Rafał Kluz and Andrzej Kubit, Department of Manufacturing and Production Engineering, Rzeszow University of Technology, Al. Powst. Warszawy 8, 35-959 Rzeszów, Poland; Tomasz Trzepiecinski, Department of Materials Forming and Processing, Rzeszow University of Technology, Al. Powst. Warsaw 8, 35-959 Rzeszów, Poland; Koen Faes, Belgian Welding Institute, Technologiepark-Zwijnaarde 935, 9052 Ghent, Belgium; and Wojciech Bochnowski, Department of Mathematics and Natural Sciences, University of Rzeszow, 1 Pigonia St., 35-310 Rzeszów, Poland. Contact e-mail: tomtrz@prz.edu.pl. distortion. In the aircraft industry, friction welding is replacing other methods of joining such as riveting, screwing and adhesive bonding because (i) RFSSW does not require additional elements, (ii) there is no need to drill the materials to be joined, and (iii) the welds do not protrude above the surface of the joined elements.

The influence of the welding process parameters on the load capacity of joints and the weld microstructure has become the focus of much research investigation (Ref 5-7). Oberembdt et al. (Ref 5) concluded that the most effective variable for controlling joint strength is plunge depth. Shen et al. (Ref 6) concluded that the overlap shear strength of single-lap joints increases with the increase in weld time and plunge depth due to increasing nugget diameter. Li et al. (Ref 8) discussed the effect of tool rotational speed on weld formation, microstructure and the mechanical properties of the RFSSW welds. They concluded that increasing the tool rotational speed decreases the lap shear load of the weld. Tier et al. (Ref 9) concluded that the plunge depth and rotational speed are the most significant variables during RFSSW.

Optimization of the FSW and RFSSW process parameters depends upon the ability to measure and control the process variables (Ref 10). To select the appropriate welding parameters, several methods can be used based on the welder's own experience and analytical and numerical methods. Some of these methods are time-consuming and expensive. An economical way to select the optimal process parameters is to conduct experiments using the design of experiments (DOE) technique (Ref 7, 10, 11).

The friction welding of Alclad aluminum alloy sheets requires special attention and precise welding procedures, different to the procedures found in the FSW process. Firstly, Alclad within the weld nugget causes heterogeneity in the structure of the weld, especially in the area of the nugget axis, because it cannot be stirred together with the base materials to an adequate extent. Secondly, the Alclad layer is characterized by a significantly higher value of thermal conductivity than the 
7075-T6 aluminum alloy. So, the heat generated in the welding process is non-uniformly distributed in the vicinity of the weld area due to the rapid dissipation of heat through the Alclad layer.

Optimization methods are applied to reduce the number of experiments and determine the maximum value of the regression function, usually taking into account only one criterion, the load capacity of the joint. The many defects which can arise in the RFSSW process are correlated with many process parameters and physical phenomena. Therefore, the aim of this paper is to present an alternative method for optimizing the parameters of the RFSSW process for joining 7075-T6 aluminum alloy sheets based on scalarization of the objective function using the weighting grades method in order to maximize the load capacity of the joint and minimize the standard deviation of the results.

\section{Materials and Methods}

\subsection{Material}

In this manuscript, 7075-T6 Alclad aluminum alloy sheets are used to produce RFSSW single-lap joints. The thicknesses of the upper and lower plates are 1.6 and $0.8 \mathrm{~mm}$, respectively. This configuration corresponds to the structure of the metal skins of an aircraft in which the stiffeners (1.6 mm thick) of the fuselage of an aircraft are connected to the skin ( $0.8 \mathrm{~mm}$ thick). The plates used in the experimental works are cut to the dimensions of $120 \times 30 \mathrm{~mm}$ (Fig. 1). During welding, all the specimens were lap combined and welded at the center of the overlap area.

The chemical composition of the sheet material is listed in Table 1. The basic mechanical properties of the sheets have been determined by uniaxial tensile tests according to the ENISO 6892-1 (Ref 12). Three samples were tested, and the average values of the basic mechanical parameters were determined: yield stress $R_{\mathrm{p} 0.2}=413.68 \mathrm{MPa}$, ultimate tensile stress $R_{\mathrm{m}}=482.6 \mathrm{MPa}$ and elongation $A=7 \%$.

\subsection{Welding Process}

The RFSSW machine used in the experimental investigation was an RPS 100 VA11 manufactured by Harms \& Wende $\mathrm{GmbH}$ and Co KG. The outer diameters of the pin and sleeve are 5.2 and $9 \mathrm{~mm}$, respectively. The RFSSW shoulder-plunge variant welding process consists of three main stages and has been described in detail by many authors (Ref 13,14$)$. In the first stage, the pin, sleeve and clamping ring move to the
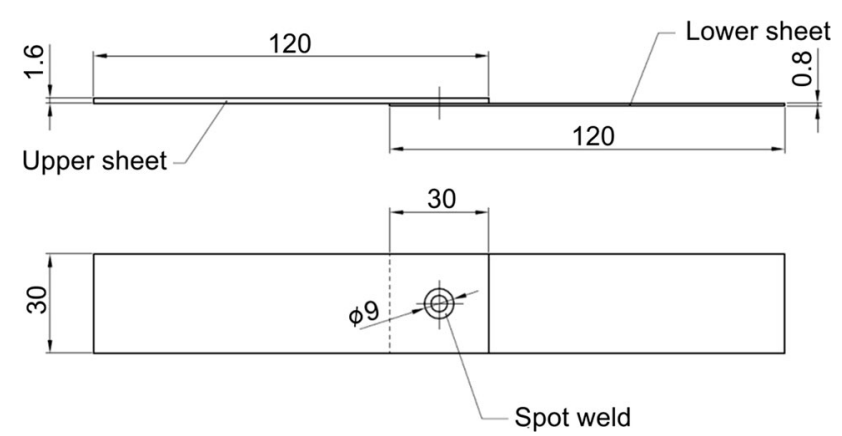

Fig. 1 The dimensions of the specimens for tensile/shear tests surface of the upper sheet. When the sheets are clamped, the pin and sleeve start to rotate for a certain time to produce frictional preheating. In the second stage (Fig. 2a), both the pin and sleeve rotate, and the sleeve is plunged to a set depth into the base material. At the same time, the pin retracts to create a free space for the displaced material to flow into (Fig. 2b). In the third stage, the direction of movement of both the sleeve and the pin begin to reverse and the plasticized material in the cylindrical cavity is squeezed back by the pin (Fig. 2c). The cross section of a typical RFSSW joint is presented in Fig. 3.

The range of changes of the welding process parameters was determined on the basis of previous research (Ref 15). The specified range corresponded to the values of the process parameters which significantly affect the load capacity of the RFSSW joint. Tool rotational speeds $n$ of 2000, 2400, $2800 \mathrm{rpm}$ and sleeve plunge depths $g$ of $1.3,1.5,1.7$ and $1.9 \mathrm{~mm}$ were applied. The duration of welding $t$ was $1.5,2.5$ and $3.5 \mathrm{~s}$. Welding tests were carried out for all combinations of the above parameters. So the total number of tests conducted was $3(n) \times 4(g) \times 3(t)=36$.

\subsection{Tensile/Shear Testing}

The investigation of the load capacity of the joint by tensile/ shear tests was carried out using a ZWICK Roell Z100 universal testing machine with a constant cross-head speed of $5 \mathrm{~mm} / \mathrm{min}$ at ambient temperature. Five samples were tested for each of the welding parameter configurations.

The fracture surface morphologies of the specimens were examined in detail using a Tescan model VEGA3 scanning electron microscope.

\section{Results of Ten Tensile/Shear Tests}

The results obtained from tests on the influence of tool rotational speed and duration of welding on the load capacity of joints are shown in Fig. 4(a) and 5. An increase in tool rotational speed causes an increase in load capacity of the joint in the case of welding durations of 1.5 and $2.5 \mathrm{~s}$. For a welding duration of $1.5 \mathrm{~s}$, an increase in tool rotational speed causes an increase in load capacity of $17.9 \%$, while for a welding duration of $2.5 \mathrm{~s}$ the increase is $11.5 \%$ (Fig. $4 \mathrm{a}$ ). In the case of welds performed with a welding duration $x_{3}=3.5 \mathrm{~s}$, it should be noted that an increase in tool rotational speed from 2000 to $2400 \mathrm{rpm}$ enabled the load capacity of the joint to increase by $8.3 \%$. A further increase in the tool rotational speed caused a reduction in load capacity of the joint by $7.25 \%$. An increase in tool rotational speed causes an increase in the weld temperature leading to better plasticization of the material and increasing strength of the joint. However, a long duration of welding causes an excessive rise in temperature and overheating of the material. A high temperature in the welding zone also causes the plasticized material to stick to the rotating tool surfaces. The sticking material also made it difficult to obtain the assumed plunge depth of the tool, and as a result a much larger dispersion of the test results was observed than is the case with joints fabricated at lower tool rotational speeds (Fig. 4b). The standard deviation of the test results was determined on the basis of five-element specimens. A smaller value of the standard deviation is associated with greater repeatability of the process, which is reflected in the reliability of the welded 


\begin{tabular}{|c|c|c|c|c|c|c|c|c|c|c|}
\hline \multirow[b]{2}{*}{$\mathbf{S i}$} & \multirow[b]{2}{*}{$\mathbf{F e}$} & \multirow[b]{2}{*}{$\mathrm{Cu}$} & \multirow[b]{2}{*}{ Mn } & \multirow[b]{2}{*}{ Mg } & \multirow[b]{2}{*}{$\mathrm{Cr}$} & \multirow[b]{2}{*}{$\mathbf{Z n}$} & \multirow[b]{2}{*}{ Ti } & \multicolumn{2}{|c|}{ Other impurities } & \multirow[b]{2}{*}{ Al } \\
\hline & & & & & & & & Single & Total & \\
\hline 0.40 & 0.50 & $1.2-2.0$ & 0.30 & $2.1-2.9$ & $0.18-0.28$ & $5.1-6.1$ & 0.30 & 0.05 & 0.15 & Rest \\
\hline
\end{tabular}

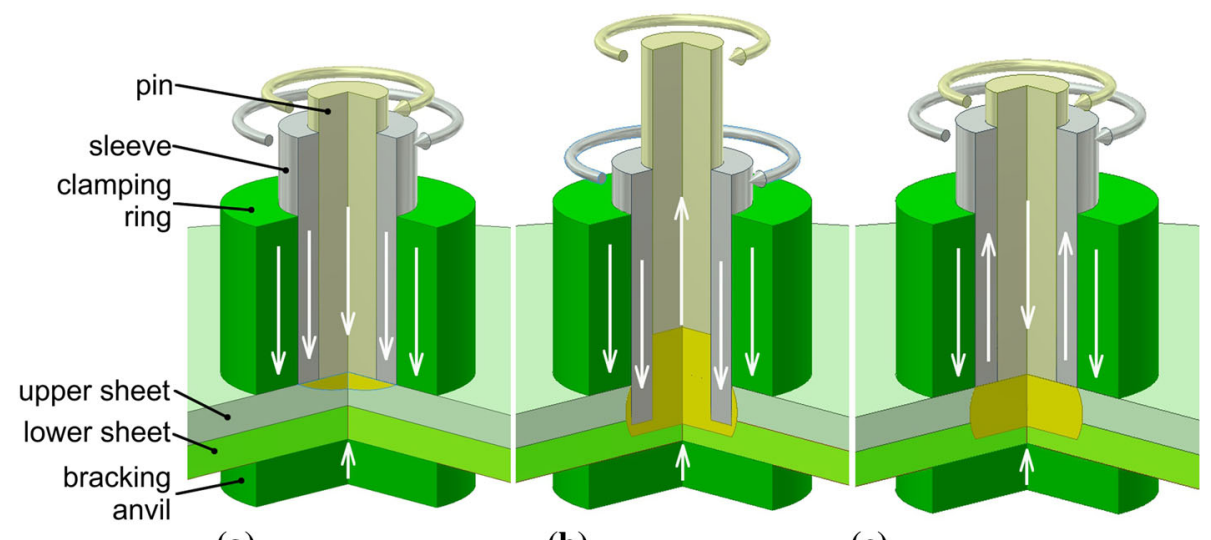

(a)

(b)

(c)

Fig. 2 Stages of the RFSSW process: (a) contact, (b) plunge and (c) refill

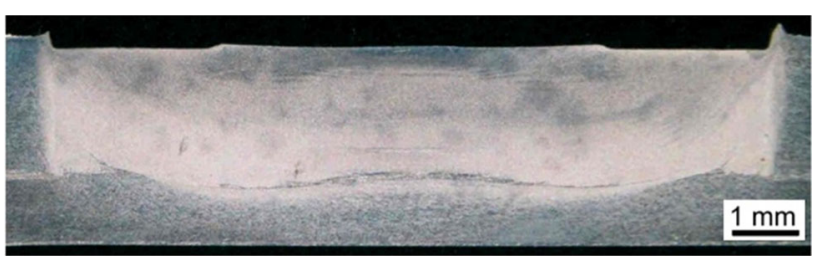

Fig. 3 Cross section of the RFSSW joint

structure of the aircraft. An evaluation of the repeatability of the process was carried out using the Hartley test. In order to verify the hypothesis about the repeatability of variance, the statistic of the $F_{\max }$ test was determined:

$F_{\text {max }}=\frac{s^{2}(y)_{i \max }}{s^{2}(y)_{i \text { min }}}$

where $s^{2}(y)_{i \max }$ and $s^{2}(y)_{i \min }$ are the maximum and minimum values from the set of all variances, respectively.

The critical values of the Hartley test $f_{\max (\mathrm{a}, \mathrm{k}, \mathrm{v})}$ for the number of degrees of freedom $k=m=36, v=r-1=5-1=4$ for the significance level $\alpha=0.05$ were read out from the statistical tables and compared with the calculated value of $F_{\text {max }}$. An analysis of the test showed that the results obtained at different values of the welding process parameters do not have the same variance $\left(F_{\max }>f_{\max (\mathrm{a}, \mathrm{k}, \mathrm{v})}\right)$.

The curves of the effect of tool plunge depth on the load capacity of the joint have the same trend (Fig. 4b). The increase in tool plunge depth from 1.3 to $1.5 \mathrm{~mm}$ produces an increase in the load capacity of the joint. The highest value of load capacity of the joint is observed for a tool plunge depth of $1.5 \mathrm{~mm}$. After exceeding this value, all characteristics show a trend to lowering of the strength of the joint as tool plunge depth increases. In the case of a curve corresponding to the highest rotational speed used, an initial significant increase in
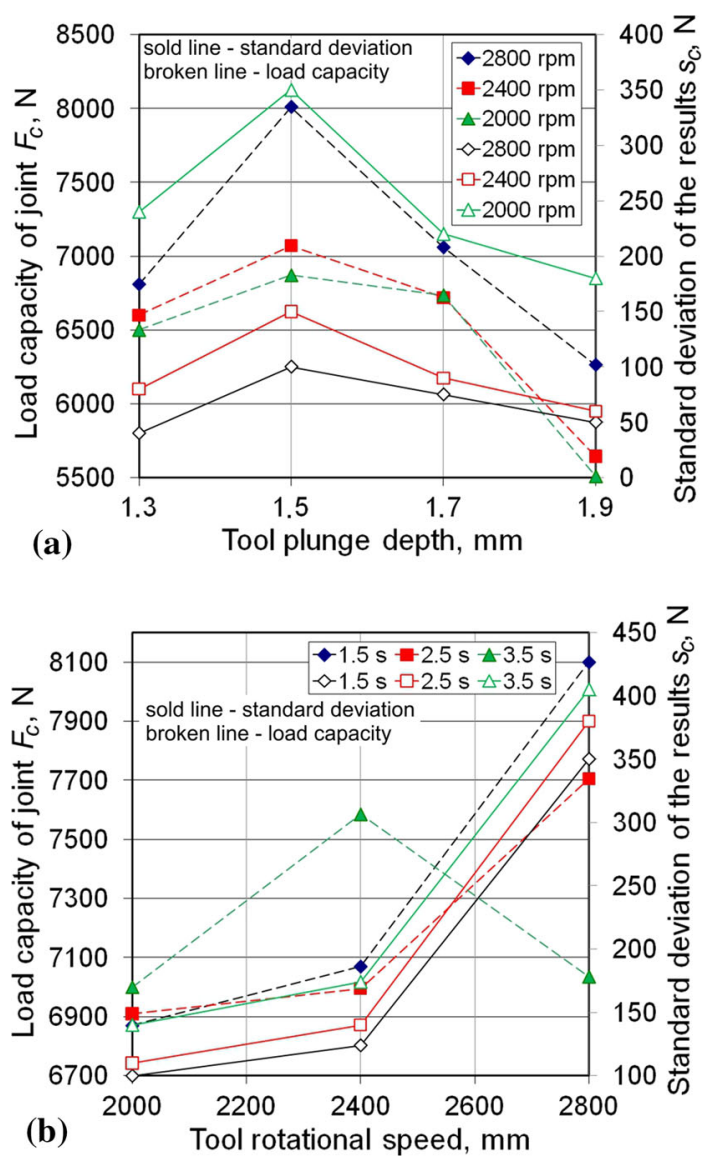

Fig. 4 Effect of tool plunge depth and tool rotational speed on the value of the load capacity of the joint and the standard deviation of the results for joints fabricated with a duration of welding of $1.5 \mathrm{~s}$ (a) and tool plunge depth of $1.5 \mathrm{~s}$ (b) 

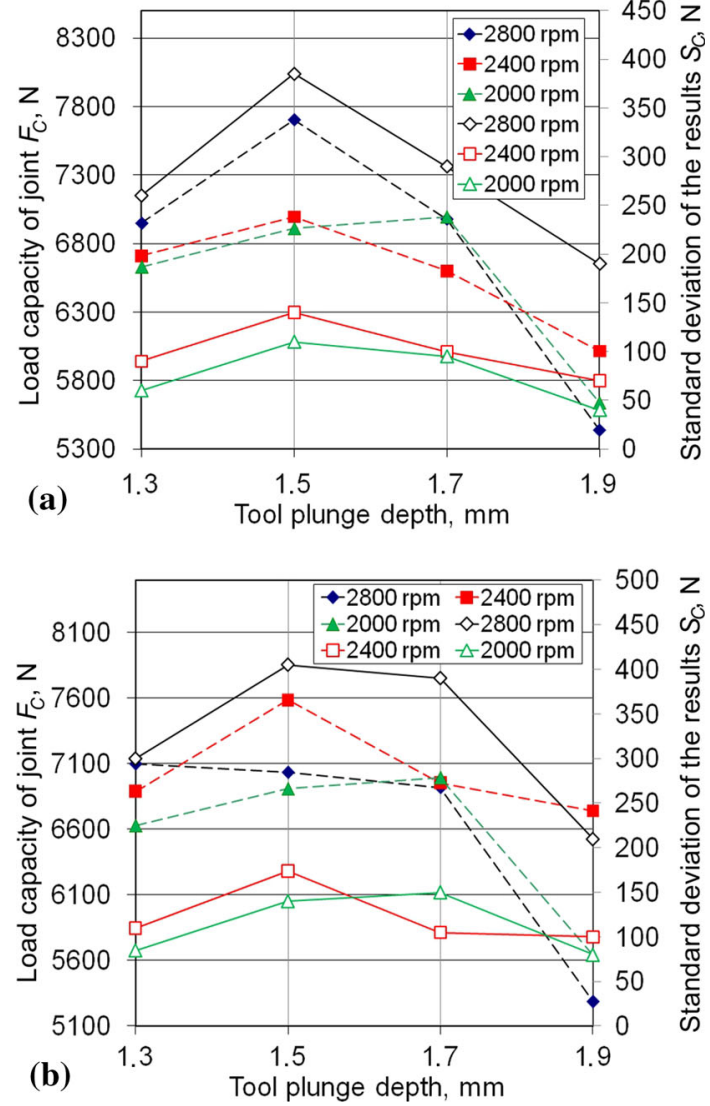

Fig. 5 Effect of tool plunge depth and tool rotational speed on the value of the load capacity of the joint and the standard deviation of the results for joints fabricated with a duration of welding of $2.5 \mathrm{~s}$ (a) $3.5 \mathrm{~s}(\mathrm{~b})$

weld strength was achieved, reaching a maximum value of $8100 \mathrm{~N}$, after which the trend reverses as the tool plunge depth increases and the joint strength decreases. The reduction in the load capacity of the joint with increasing tool plunge depth is caused by a weakening of the bottom part of the weld by the operation of the sleeve in the second stage of welding (Fig. 2b). Analysis of the test results also indicated some dependence regarding the values of variance and standard deviation. Apart from the assumed tool rotational speed, the highest standard deviation value was observed for a tool plunge depth of $1.5 \mathrm{~mm}$, i.e., at the plunge depth ensuring the highest load capacity of the joint (Fig. 4b).

A cross section of the spot weld reveals four metallurgical zones: the base material (BM), heat-affected zone (HAZ), thermomechanically affected zone (TMAZ) and stir zone (SZ). In the cross section of an RFSSW joint, four principal geometric and metallurgical features can be found: partial bonding (PB), hooks (Hs), lack of mixing (LM) and bonding ligaments (BLs) (Fig. 6).

These features have a significant effect on joint failure strength under tensile/shear loading by affecting the fracture mechanism. Partial bonding is a transition region formed when the plasticized material is pushed back to its original position by the pin in the refill stage of the welding (Fig. 2c). The connection between sheets in this region is not very strong. The hook is formed during deformation of the lower sheet during the last stage of welding, when the pin pushes the material,

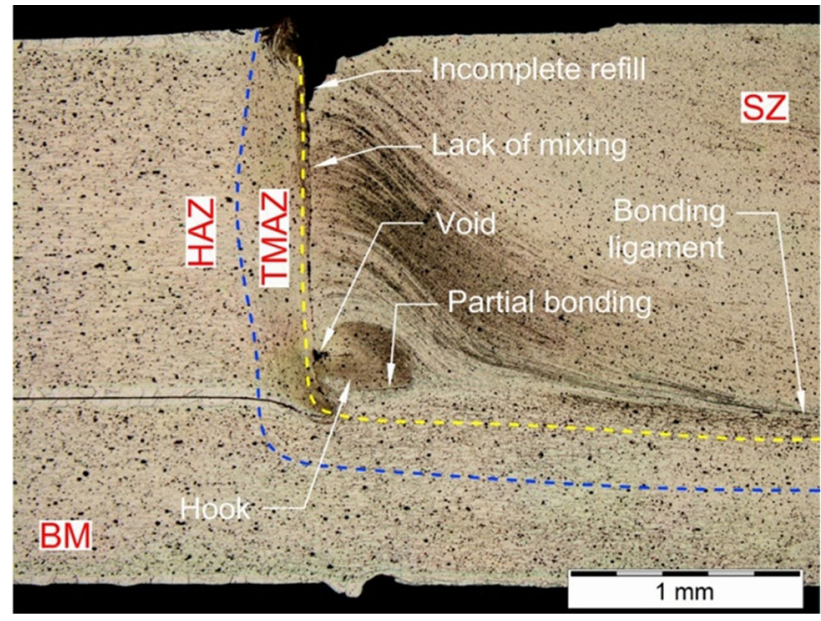

Fig. 6 Cross section of the RFSSW joint showing the main weld defects

leading to bending of the sheet interface. A bonding ligament is composed of pure aluminum, whose properties are different in relation to the BM (7075-T6 aluminum alloy). The thickness of the bonding ligament decreases with increasing duration of welding and tool rotational speed. Voids (Vs) and incomplete refilling (IR) can be attributed to insufficient flow of the SZ material at the refilling stage and a poor metallurgical bonding effect and residual heat stress after welding (Ref 13).

For tensile/shear tested specimens, three main types of failure mechanisms were revealed: interfacial failure (IF), plug failure (PF) and U-shape or L-shape pullout failure, denoted as U-type POF and L-type POF, respectively. Table 2 summarizes the fracture modes of the welds investigated. The first mechanism is characterized by failure via crack propagation through the weld (Fig. 7a). In the second case, joints will fail as a PF, a plug is characterized by the weld zone tearing clear of one of the sheets leaving a visible protrusion (Fig. 7b). Pullout failure occurs via complete withdrawal of the weld nugget from the sheet (Fig. 7c and d).

Interfacial failure is the main mechanism of failure which was observed in the case of the welds fabricated at a sleeve plunge depth lower than that of the upper sheet thickness. However, pullout failure was observed in the case of welds fabricated at sleeve plunge depths of 1.3 or $1.5 \mathrm{~mm}$ and the highest values of tool rotational speed $(2800 \mathrm{rpm})$ and duration of welding $(3.5 \mathrm{~s})$. Both high welding time and high tool rotational speed led to a recrystallization process caused by high temperature. So, a fine-grained structure with higher mechanical strength than BM is observed in the weld. The tear plug fracture with a tear on the lower sheet is the preferred failure mode due to its higher associated plastic deformation and energy absorption.

Increasing the sleeve plunge depth to a value higher than the thickness of the upper sheet causes the existence of a clear structural notch on the perimeter of the weld where the edge of the sleeve cuts the lower sheet. In this region, the BM material is not sufficiently plasticized and mixed in the weld region. Complete or partial plug failure is then observed in the area of the lower sheet. A lack of sufficient mixing of material between both stir and thermomechanically affected zones due to low tool rotational speed or duration of welding is the principal cause of plug fracture mode. 
Table 2 Effect of process parameters on the type of failure mechanism and formation of main defects

\begin{tabular}{|c|c|c|c|c|c|}
\hline Test no. & $\begin{array}{l}\text { Tool rotational } \\
\text { speed } n, \text { rpm }\end{array}$ & $\begin{array}{l}\text { Sleeve plunge } \\
\text { depth } g, \mathrm{~mm}\end{array}$ & $\begin{array}{l}\text { Duration of } \\
\text { welding } t, \mathrm{~s}\end{array}$ & $\begin{array}{c}\text { Failure } \\
\text { mechanism }\end{array}$ & $\begin{array}{c}\text { Weld } \\
\text { characterization }\end{array}$ \\
\hline 1 & 2000 & 1.3 & 1.5 & IF & BL, LM, IR \\
\hline 2 & 2000 & 1.3 & 2.5 & IF & BL, LM, IR \\
\hline 3 & 2000 & 1.3 & 3.5 & IF & BL, LM \\
\hline 4 & 2000 & 1.5 & 1.5 & IF & BL, LM, IR \\
\hline 5 & 2000 & 1.5 & 2.5 & IF & BL, LM, IR \\
\hline 6 & 2000 & 1.5 & 3.5 & IF & $\mathrm{BL}$ \\
\hline 7 & 2000 & 1.7 & 1.5 & $\mathrm{PF}$ & BL, LM \\
\hline 8 & 2000 & 1.7 & 2.5 & $\mathrm{PF}$ & $\mathrm{BL}$ \\
\hline 9 & 2000 & 1.7 & 3.5 & U-type POF & LM \\
\hline 10 & 2000 & 1.9 & 1.5 & $\mathrm{PF}$ & BL, LM \\
\hline 11 & 2000 & 1.9 & 2.5 & U-type POF & $\mathrm{BL}$ \\
\hline 12 & 2000 & 1.9 & 3.5 & U-type POF & $\mathrm{BL}$ \\
\hline 13 & 2400 & 1.3 & 1.5 & IF & BL, IR \\
\hline 14 & 2400 & 1.3 & 2.5 & IF & $\mathrm{BL}$ \\
\hline 15 & 2400 & 1.3 & 3.5 & IF & Vs \\
\hline 16 & 2400 & 1.5 & 1.5 & IF & BL, IR \\
\hline 17 & 2400 & 1.5 & 2.5 & IF & BL, IR \\
\hline 18 & 2400 & 1.5 & 3.5 & $\mathrm{PF}$ & Vs \\
\hline 19 & 2400 & 1.7 & 1.5 & $\mathrm{PF}$ & BL, IR \\
\hline 20 & 2400 & 1.7 & 2.5 & $\mathrm{PF}$ & BL, IR \\
\hline 21 & 2400 & 1.7 & 3.5 & U-type POF & $\mathrm{BL}$ \\
\hline 22 & 2400 & 1.9 & 1.5 & $\mathrm{PF}$ & Vs \\
\hline 23 & 2400 & 1.9 & 2.5 & U-type POF & $\mathrm{BL}$ \\
\hline 24 & 2400 & 1.9 & 3.5 & U-type POF & $\mathrm{BM}, \mathrm{Vs}$ \\
\hline 25 & 2800 & 1.3 & 1.5 & IF & $\mathrm{BL}$ \\
\hline 26 & 2800 & 1.3 & 2.5 & IF & $\mathrm{BL}$ \\
\hline 27 & 2800 & 1.3 & 3.5 & IF & $\mathrm{H}, \mathrm{PB}$ \\
\hline 28 & 2800 & 1.5 & 1.5 & IF & $\mathrm{BL}$ \\
\hline 29 & 2800 & 1.5 & 2.5 & IF & $\mathrm{BL}$ \\
\hline 30 & 2800 & 1.5 & 3.5 & L-type POF & $\mathrm{H}, \mathrm{PB}$ \\
\hline 31 & 2800 & 1.7 & 1.5 & $\mathrm{PF}$ & $\mathrm{BL}$ \\
\hline 32 & 2800 & 1.7 & 2.5 & U-type POF & $\mathrm{PB}$ \\
\hline 33 & 2800 & 1.7 & 3.5 & U-type POF & PB \\
\hline 34 & 2800 & 1.9 & 1.5 & $\mathrm{PF}$ & $\mathrm{BL}$ \\
\hline 35 & 2800 & 1.9 & 2.5 & U-type POF & PB \\
\hline 36 & 2800 & 1.9 & 3.5 & U-type POF & $\mathrm{PB}$ \\
\hline
\end{tabular}

Figure 8, 9, 10 summarizes the selected fractures of the welds destroyed by the three main types of failure mechanism. The notations of the weld fractures correspond to the parameters listed in Table 2. The surfaces of the welds destroyed by interfacial failure are characterized by ductile fracture (Fig. 8). In the case of the specimens fabricated at the sleeve plunge depth of $1.5 \mathrm{~mm}$ (Fig. 8d), the fracture surfaces are characterized by the presence of Alclad layer mixed in BM. The center area of the fracture surface is also contaminated by randomly distributed small fragments of oxides which originally were located on the surface of the Alclad layer.

The fracture surface of the specimens destroyed by the mechanism of plug failure is characterized by dimples (Fig. 9) which are located around the perimeter of the weld. The size and shape of the dimples depend on the direction of the stress interaction. The dimples are typical for the ductile type of fracture and are mainly located in the TMAZ of the weld.

The crack initiation of the specimens destroyed by pullout failure was located in the vicinity of the weld periphery in which the fine-grained structure is observed. The material with finegrained structure is characterized by higher mechanical strength than BM, and the combined brittle-ductile fracture type can be revealed in the micrographs (Fig. 10). The inhomogeneity of the weld structure around its periphery is a result of the presence of aluminum oxides which are a source of crack nucleation.

\section{Regression Analysis}

The selection of the optimal parameters of the RFSSW process requires the determination of an adequate mathematical model in the form of a regression function $W(x)$. Regression analysis has been carried out using the least squares method. The criterion for assessing the quality of the approximation takes the form:

$\min R=\min \sum_{i=0}^{N}\left[f\left(x_{1}\right)-W\left(x_{1}\right)\right]^{2}$

where the value of function $R$ is a certain measure of the deviation of the approximation function $W(x)$ and approximated function $f(x), i=1, \ldots, N$ number of experiments.

For the needs of statistical analysis, the following designation was adopted: tool rotational speed $x_{1}$, plunge depth $x_{2}$ and duration of welding $x_{3}$. 


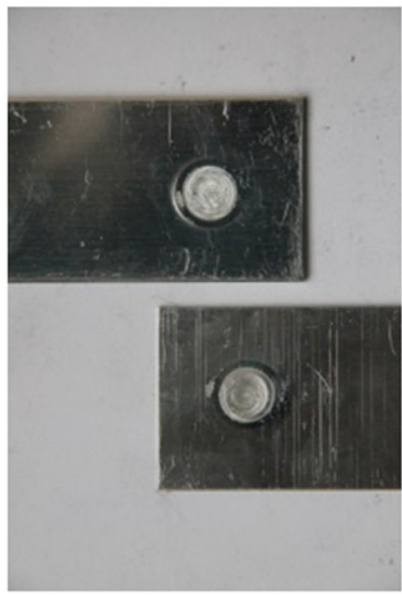

(a)

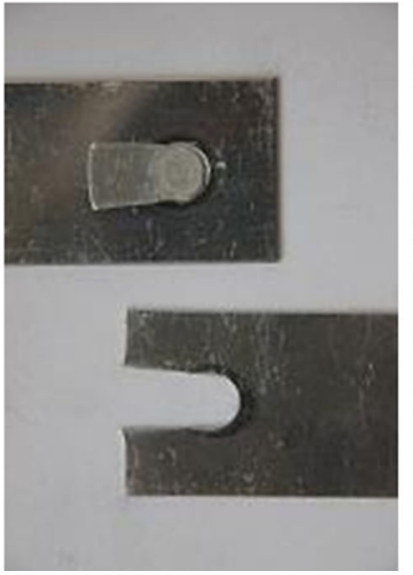

(c)

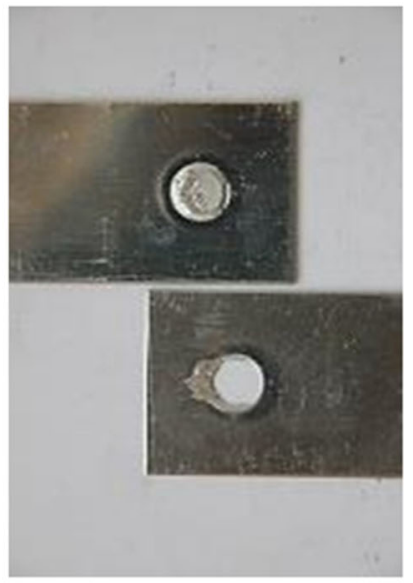

(b)

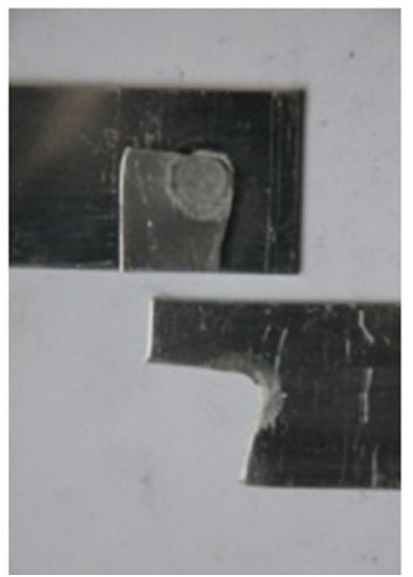

(d)

Fig. 7 Typical failure modes observed during tensile/shear tests between upper (on top) and lower (at the bottom) sheets: interfacial failure (a), plug failure (b), U-type (c) or L-type (d) pullout failure

During the approximation, the most frequently selected basic functions are monomials according to Weierstrass's theorem. This theorem defines that for every function $f(x)$ specified and continuous on a closed and limited interval $[\mathrm{a}, \mathrm{b}]$ exists a polynomial $W=b_{0}+b_{1} x_{1}+b_{\mathrm{m}} x^{\mathrm{m}}$ that approximates monotonously the function $f(x)$ on the interval $[\mathrm{a}, \mathrm{b}]$. During the analysis, however, it was not possible to obtain such a polynomial with a rational $m$ level, which could be considered as adequate. Therefore, the m-degree algebraic polynomial was adopted for the definition of the interactions between the RFSSW process parameters:

$$
\begin{aligned}
W(x)= & b_{0}+\sum_{i=1}^{S} b_{i}^{(1)} x_{i}+\sum_{\substack{i, j=1 \\
i<j}}^{S} b_{i j}^{(1)} x_{i} x_{i} \\
& +\sum_{\substack{i, j, \ldots l, n=1 \\
i<j, \ldots, l<n}}^{S} b_{i j \ldots \ln }^{(1)} x_{i} x_{j} \ldots x_{l} x_{n}+\sum_{\substack{i, j=1 \\
i \neq j}}^{S} b_{i j}^{(2)} x_{i}^{2} x_{j} \\
& +\sum_{\substack{i=1 \\
S}}^{S} b_{i i \ldots . .}^{(m)} x_{i}^{m}
\end{aligned}
$$

In Eq 3 , there exists $L$-number of unknown coefficients $b_{0}, b_{i}^{(1)}, b_{i j}^{(1)}, b_{i j \ldots \ln }^{(1)}, b_{i j}^{(2)}, b_{i i \ldots m}^{(m)}$ while $i, j, \ldots, n=1, \ldots, S$ variables of a polynomial (3).

The Fisher-Snedecor test was used to assess the adequacy of the regression equation with the test results. At the first stage of the analysis, the adequacy variance was determined, according to the following formula:

$S_{\mathrm{ad}}^{2}=\frac{r \sum_{i=1}^{N}\left(\bar{y}_{1}-\overline{\overline{y_{1}}}\right)^{2}}{N-k-1}$

where $\bar{y}_{i}$ is average value of measurement results in the $i$-th experiment, $\overline{\overline{y_{1}}}$ is value calculated from the regression equation for the levels of input and output factors in $i$-th experiment, $k$ is number of terms in regression equation (without a free term) after rejection of insignificant terms and $N$ the total number of experiments.

Then the value determined for the test coefficient $F$ :

$F=\frac{S_{\mathrm{ad}}^{2}(y)}{S^{2}(y)}$

was compared with the critical value determined from the Fisher-Snedecor distribution table. This allowed an adequate regression equation to be obtained describing the influence of the RFSSW process parameters on the load capacity of joints $\left(W_{F}(x)\right)$ and standard deviation of the load capacity $\left(W_{\sigma}(x)\right)$, with the following form:

$$
\begin{aligned}
W_{F}(x)= & 18709.7-20.864 x_{1}+2806.41 x_{2}-7009.42 x_{3} \\
& +31.52 x_{1} x_{2}+10.731 x_{1} x_{3}-1029.58 x_{2} x_{3} \\
& -0.0042 x_{1}^{2} x_{2}-2.877 x_{2}^{2} x_{1} \\
& -0.0019 x_{1}^{2} x_{3}+1187.5 x_{2}^{2} x_{3}-0.0065 x_{1}^{2} \\
& -14944.4 x_{2}^{2}-1899.49 x_{3}^{2}+2.49 x_{1}^{3} \\
& -14944.4 x_{2}^{3}+263.599 x_{3}^{3} \\
W_{\sigma}(x)= & 8975.91-0.9202 x_{1}+18878.1 x_{2}-132.991 x_{3} \\
& -0.3435 x_{1} x_{2}-0.1161 x_{1} x_{3}-204.167 x_{2} x_{3} \\
& +0.0828 x_{1} x_{2} x_{3}+1.668 x_{1}^{2} x_{2}^{2}+176.989 x_{3}^{2} \\
& +5.3109 \cdot 10^{-8} x_{1}^{3}+2094.91 x_{2}^{3}-22.2929 x_{3}^{3}
\end{aligned}
$$

The maximum error value of the regression function did not exceed $6.11 \%$, while the mean square error between the experimental results and the results of mathematical modeling was $2.55 \%$.

\section{Multicriteria Optimization}

In order to replace classic resistance welding by RFSSW technique, thus ensuring a better quality of welds, it is necessary to select optimal welding parameters. This selection must guarantee not only a high load capacity of the joints produced, but also high process stability, characterized by the lowest possible value of the variance of the results obtained. This requires multicriteria optimization of the process and finding a compromise solution that meets the aforementioned mathematical model.

For the writing of the multicriteria problem, the following designations have been adopted: 

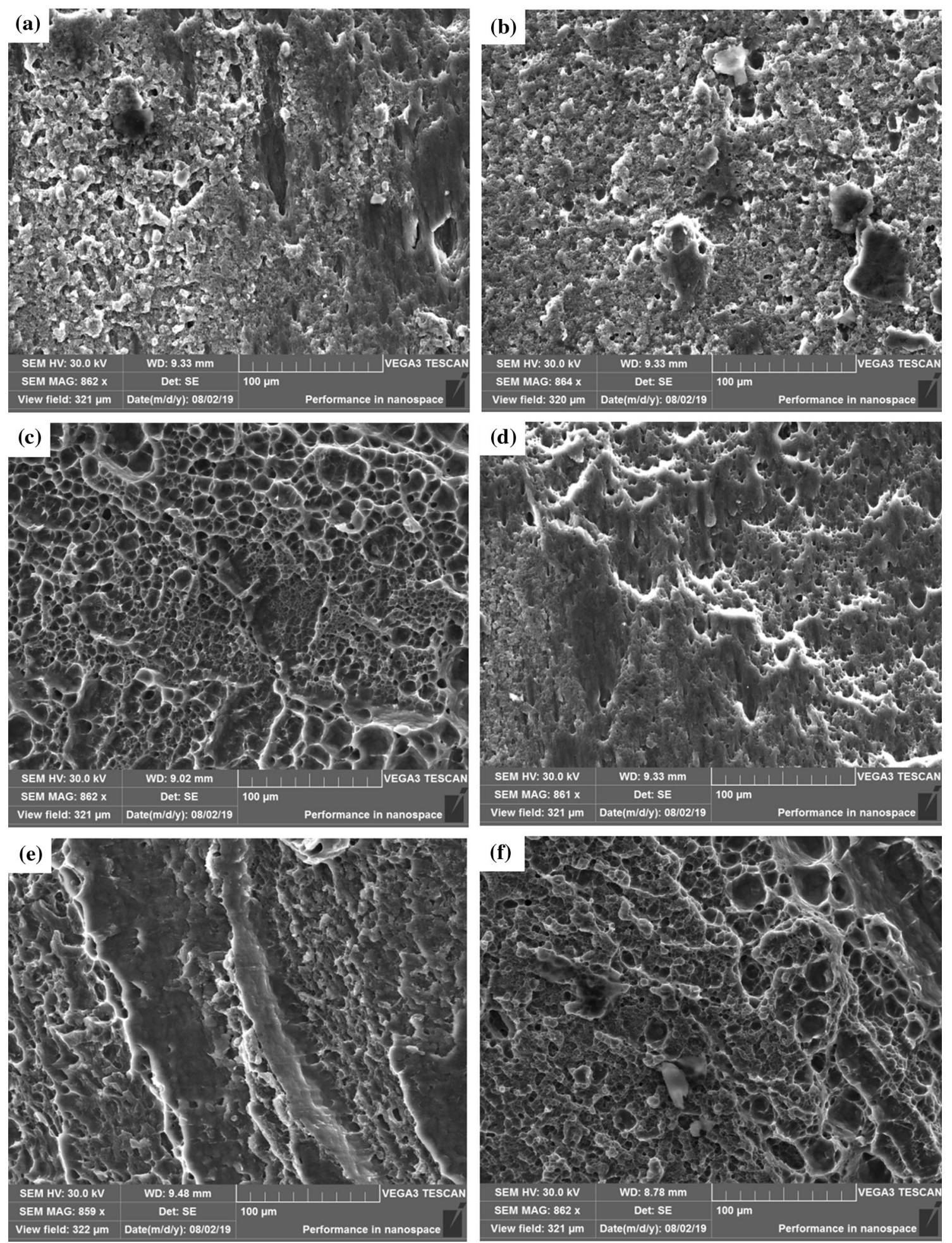

Fig. 8 SEM micrograph of the fracture of welds destroyed by the mechanism of interfacial failure; number of specimens (according to Table 2): (a) 2, (b) 6, (c) 14, (d) 17, (e) 25, (f) 28

- $\quad D \subset R^{m}$ a set of permissible solutions (a range of process setting parameters),

- $z=\left(z_{1}, z_{2}, \ldots, z_{m}\right) \in D$ acceptable solution,

- $f_{i}: D \rightarrow R i$-th objective function $(i=1,2, \ldots, k)$,

- $(z)=\left(f_{1}(z), f_{2}(z)\right.$ the objective function for multicriteria problem.
The problem of multicriteria optimization of the selection of process parameters can be written in the form of:

$\left\{\begin{array}{l}f_{1}(z)=W_{F}(x) \rightarrow \max , \\ f_{2}(z)=W_{\sigma}(x) \rightarrow \min , \\ z \in D\end{array}\right.$ 

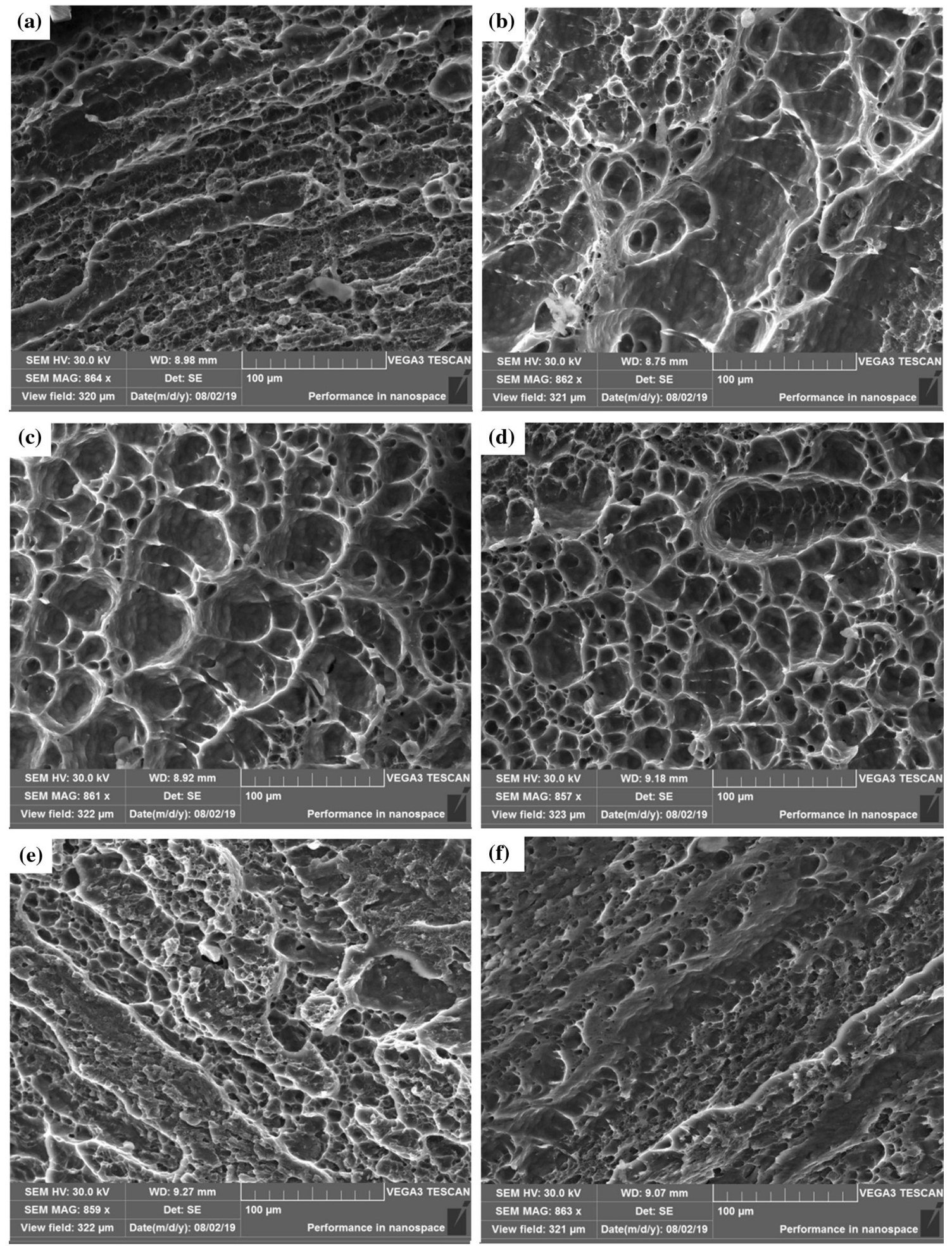

Fig. 9 SEM micrograph of the fracture of welds destroyed by the mechanism of plug failure; number of specimens (according to Table 2): (a) 7, (b) 8, (c) 10, (d) 19, (e) 20, (f) 34

The one-criteria problem:

$f_{i}(z) \rightarrow$ ekstremum, $z, \in D$

is an $i$-th partial problem, where the vector $z^{i o} \in D$ in which the $i$-th objective function reaches the extremum searched.
The function describing the load capacity of the joint $W_{F}(x)$ reaches a maximum value of $7759.54 \mathrm{~N}$ at a tool rotational speed $x_{1}=2800 \mathrm{rpm}$, tool plunge depth $x_{2}=1.55 \mathrm{~mm}$ and duration of welding $x_{3}=1.58 \mathrm{~s}$. In contrast, the minimum load capacity of $5456.25 \mathrm{~N}$ is observed at $x_{1}=2000 \mathrm{rpm}$, $x_{2}=1.9 \mathrm{~mm}$ and $x_{3}=1.5 \mathrm{~s}$. The maximum and minimum values of the $W_{F}(x)$ function correspond to the extreme values 

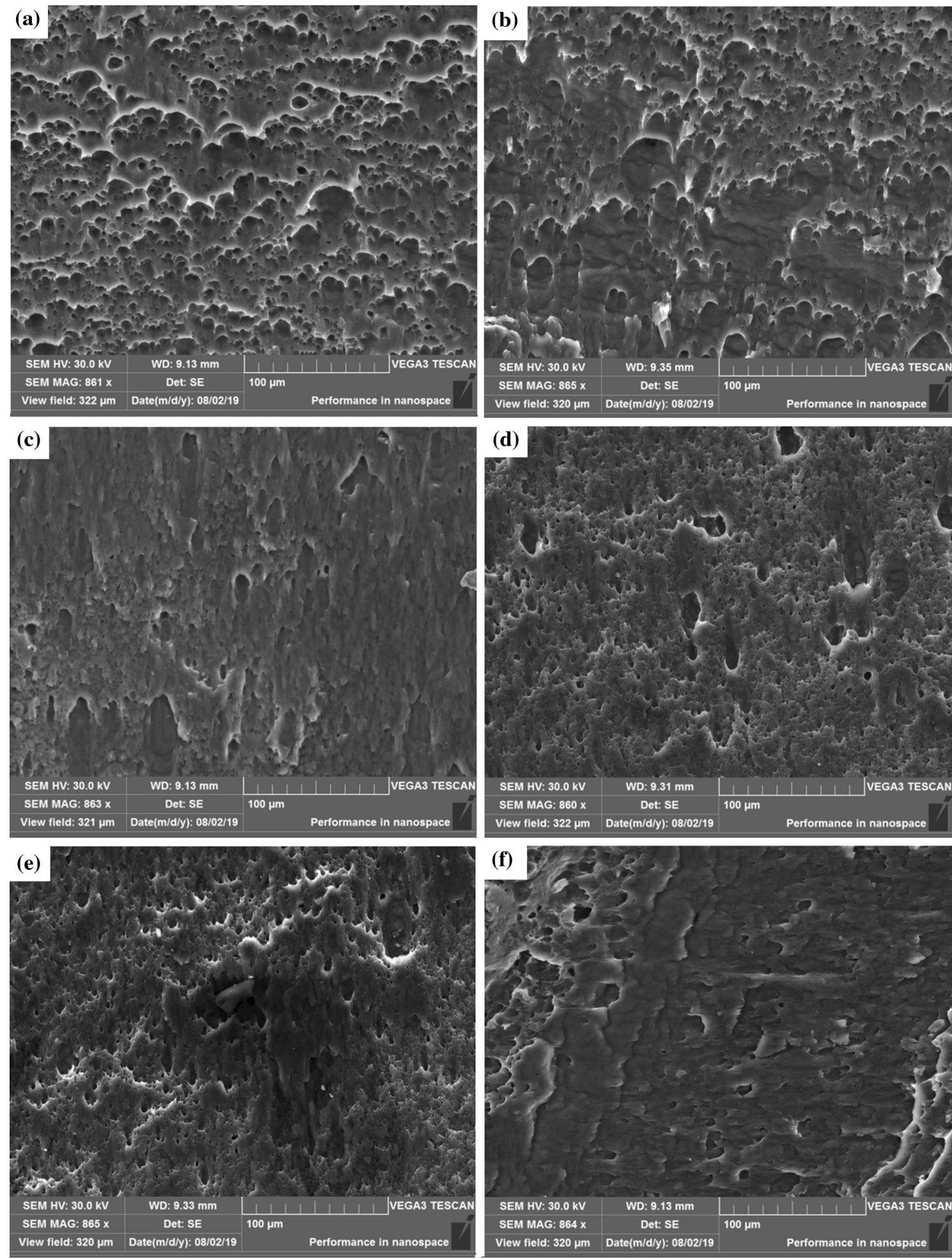

Fig. 10 SEM micrograph of the fracture of welds destroyed by the mechanism of pullout failure; number of specimens (according to Table 2): (a) 9, (b) 12, (c) 21, (d) 24, (e) 32, (f) 35

of the RFSSW process parameters at which the tests were carried out. The second function describing the standard deviation of the results of the load capacity $W_{\sigma}(x)$ of the joint takes the highest value of $374.71 \mathrm{~N}$ at a tool rotational speed $x_{1}=2800 \mathrm{rpm}$, tool plunge depth $x_{2}=1.47 \mathrm{~mm}$ and duration of welding $x_{3}=3.5 \mathrm{~s}$, while the minimum value of $16.67 \mathrm{~N}$ is found to be at $x_{1}=2241.35 \mathrm{rpm}, x_{2}=1.9 \mathrm{~mm}$ and $x_{3}=1.87 \mathrm{~s}$.
Usually the ideal solution of function (9) is not available, which means that in the set of permissible solutions $D$, there is no vector $z^{\circ}$ for which all objective functions reach the extreme searched for. Therefore, a search was made for effective solutions during the solution of the problem being examined. The aim of the methodology presented in the article was to select one optimal solution from the set of effective solutions. 
Goal programming was applied to solve the problem being studied. In goal programming, the main control parameters are aspiration levels treated as goals to be achieved for individual assessment functions. An aspiration level $a_{i}$ was assumed for each assessment function $f_{i}(z)$. For each permissible solution $z \in$ $D$, the deviations downwards and upwards of the assessment function $f_{i}(z)$ from the aspiration levels are defined as:

$d_{i}^{-}=a_{i}-f\left(z_{i}\right)$

$d_{i}^{+}=f\left(z_{i}\right)-a_{i}$

An optimal solution of the problem being studied is the permissible solution which minimizes the deviations from the aspiration levels. As a goal function, a weighted sum of deviations was adopted:

$g\left(d^{-}, d^{+}\right)=\sum_{i=1}^{m}\left(u_{i} d^{-}+u_{i} d^{+}\right)$

where $u_{i}$ are non-negative weights corresponding to individual deviations.

Deviations were introduced into the goal programming model by means of an additional system of goal equations:

$f\left(z_{i}\right)+d_{i}^{-}+d_{i}^{+}=a_{i}$

$d_{i}^{-} \geq 0, d_{i}^{+} \geq 0$

$d_{i}^{-} d_{i}^{+}=0$

where $d_{i}^{-}, d_{i}^{+}$are non-negative state variables expressing, respectively, the upper and lower deviation of the current value of the $i$-th assessment function from the appropriate level of aspiration $a_{i}$.

In order to find an optimal (compromise) solution, the method of weighting of the goal variable was applied. So the set of equations of the problem takes the form:

$\left\{\begin{array}{l}u_{1} \cdot\left(d_{1}^{+}+d_{1}^{-}\right)+u_{2} \cdot\left(d_{2}^{+}+d_{2}^{-}\right) \rightarrow \min \\ W_{F}(x)+d_{1}^{+}-d_{1}^{-}=a_{1} \\ W_{\sigma}(x)+d_{2}^{+}-d_{2}^{-}=a_{2} \\ 2000 \leq x_{1} \leq 2800 \\ 1.3 \leq x_{2} \leq 1.9 \\ 1.5 \leq x_{3} \leq 3.5 \\ d_{1}^{+} d_{1}^{-}=0 \\ d_{2}^{+} d_{2}^{-}=0 \\ x_{1}, x_{2}, x_{3} \geq 0 \\ d_{1}^{+}, d_{1}^{-}, d_{2}^{+}, d_{2}^{-} \geq 0\end{array}\right.$

The form of the solution (12) depends on the weight value $u_{i}$ and the levels of aspiration $a_{i}$ adopted. During the calculations, it was assumed that the load capacity of the RFSSW joint is more important than the variance of the welding process $\left(u_{1}=0.6, u_{2}=0.4\right)$. In the first stage of the calculations, the level of aspiration regarding the load capacity of the joint was assumed to be $a_{1}=7300 \mathrm{~N}$ and the variance of the process $a_{2}=100 \mathrm{~N}$. A solution slightly deviating from the required levels was obtained, which provided a joint load capacity of $7299 \mathrm{~N}$ with a standard deviation of $112.31 \mathrm{~N}$ (Table 3). Decreasing the level of aspiration regarding the load capacity of the joint to $7200 \mathrm{~N}$ provides a solution $\left(x_{1}=2182 \mathrm{rpm}\right.$, $\left.x_{2}=1.7 \mathrm{~mm}, x_{3}=3.5 \mathrm{~s}\right)$ much closer to the requirements (Fig. 11). In the case considered here, the load capacity of the joint deviates from the assumed one by $0.0027 \mathrm{~N}$, and the standard deviation by $0.149 \mathrm{~N}$.

A change in the aspiration levels to $a_{1}=7400 \mathrm{~N}$ and $a_{2}=140 \mathrm{~N}$ moves the optimal solution to a point corresponding to a tool rotational speed $x_{1}=2216 \mathrm{rpm}, x_{2}=1.55 \mathrm{~mm}$ and $x_{3}=3.46 \mathrm{~s}$ (point P4 in Fig. 12). By applying the parameter settings for the welding process given above, it is possible to obtain a joint load capacity of $7400 \mathrm{~N}$ with a standard deviation of the tensile/shear test results of $152.46 \mathrm{~N}$. To validate the results obtained by the goal programming, six experiments have been carried out with the process parameters given above. The average results of tensile/shear tests were: maximum load capacity of the joint $7115 \mathrm{~N}$ and standard deviation $102.3 \mathrm{~N}$. The load capacity is overestimated by the analytical model; however, the standard deviation value is lower than the numerical ones.

The problem presented in the paper was considered from the point of view of a technologist whose task is to determine the process parameters that ensure the load capacity of joint required by the constructor while ensuring the required welding process capability. In the case considered, it was assumed that the required load capacity of the joint is $7400 \mathrm{~N}$ with a standard deviation of $140 \mathrm{~N}$. During the calculations one can also assume much higher requirements of load capacity of the joint (from those accepted by the constructor), which allows one to obtain solution results similar to the values obtained during the experiment. Such a solution is not only burdened with a larger standard deviation of the results but also it results in a higher labor demand in the welding process because it requires a much higher rotational speed which increases the amount of heat emission. This process also causes significant plasticization of the material which tends to stick to the working surfaces of the tool and requires frequent cleaning of the tool, which increases the labor demand of the RFSSW process and reduces its durability. So, in the case of the parameters considered, the maximum load capacity obtained experimentally was not the most advantageous solution.

\section{Summary and Conclusions}

The article presents the results of research aimed at optimizing RFSSW process parameters in order to provide the highest possible load capacity of the joint and at the same time the smallest standard deviation of the tensile/shear test results. The analyses carried out allow one to draw the following conclusions:

1. The rotational speed of the tool determines the formation of a suitable temperature in the area of the weld that permits proper stirring and plasticizing of the BMs. At the same time, too high a tool rotational speed and too long a duration of welding disadvantageously affects the weld microstructure and causes a decrease in load capacity of the joint.

2. Another way to increase the load capacity of the joint is to extend the welding time at a constant rotational speed of the tool. The results obtained for the load capacity of welds made under such conditions are characterized by a smaller standard deviation.

3. The results are very sensitive to changes in the aspiration levels. Multicriteria optimization via goal programming allows one to determine the RFSSW process parameters 
Table 3 Results of multicriteria optimization

\begin{tabular}{llccl}
\hline Case & $\begin{array}{c}\text { Aspiration } \\
\text { level } \mathbf{a}_{\boldsymbol{i}}\end{array}$ & $\begin{array}{c}\text { Value of objective } \\
\text { function }\end{array}$ & Solution (optimal parameters) & Deviations $\boldsymbol{d}_{\boldsymbol{i}}^{+}, \boldsymbol{d}_{\boldsymbol{i}}^{-}$ \\
\hline $\mathrm{P} 1$ & $\begin{array}{l}a_{1}=7300 \mathrm{~N} \\
a_{2}=100 \mathrm{~N}\end{array}$ & 4.93 & $x_{1}=2223 \mathrm{rpm}, x_{2}=1.67 \mathrm{~mm}, x_{3}=3.5 \mathrm{~s}$ & $d_{1}^{+}=0.0016, d_{1}^{-}=0, d_{2}^{+}=0, d_{2}^{-}=12.34$ \\
$\mathrm{P} 2$ & $\begin{array}{l}a_{1}=7200 \mathrm{~N} \\
a_{2}=100 \mathrm{~N}\end{array}$ & 0.59 & $x_{1}=2182 \mathrm{rpm}, x_{2}=1.7 \mathrm{~mm}, x_{3}=3.5 \mathrm{~s}$ & $d_{1}^{+}=0.0027, d_{1}{ }^{-}=0, d_{2}^{+}=0, d_{2}^{-}=1.495$ \\
P3 & $\begin{array}{l}a_{1}=7500 \mathrm{~N} \\
a_{2}=140 \mathrm{~N}\end{array}$ & 17.995 & $x_{1}=2297 \mathrm{rpm}, x_{2}=1.55 \mathrm{~mm}, x_{3}=3.5 \mathrm{~s}$ & $d_{1}^{+}=22.35, d_{1}^{-}=0, d_{2}^{+}=0, d_{2}^{-}=0$ \\
P4 & $\begin{array}{l}a_{1}=7400 \mathrm{~N} \\
a_{2}=140 \mathrm{~N}\end{array}$ & 0 & $x_{1}=2216 \mathrm{rpm}, x_{2}=1.55 \mathrm{~mm}, x_{3}=3.46 \mathrm{~s}$ & $d_{1}^{+}=0, d_{1}^{-}=1.58 \cdot 10^{-14}, d_{2}^{+}=0, d_{2}^{-}=11.46$ \\
\hline
\end{tabular}

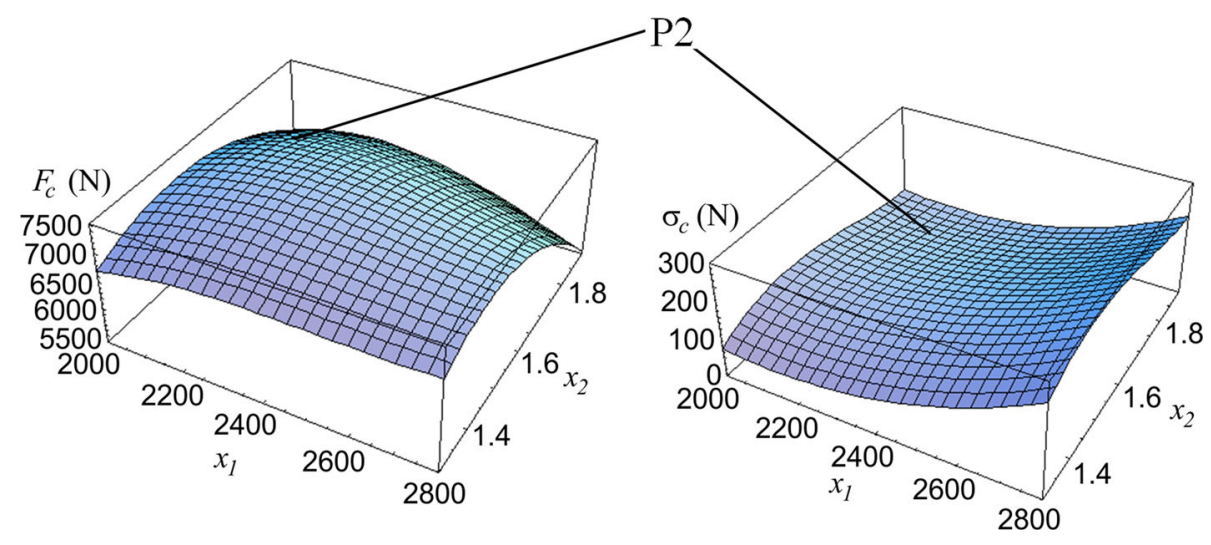

Fig. 11 Result of the solution of goal programming (Table 3, case P2)

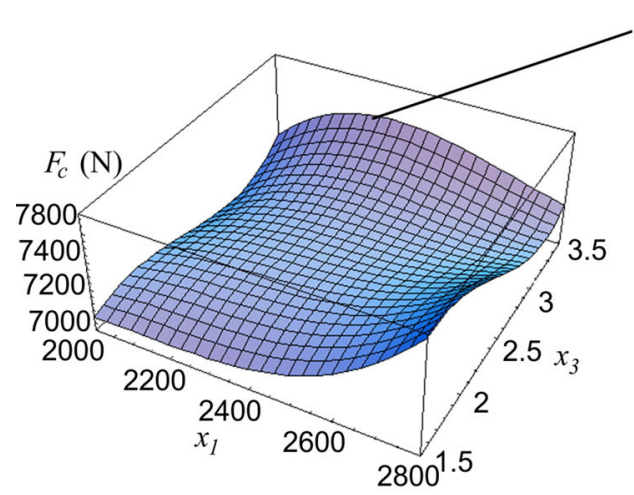

Fig. 12 Result of the solution of goal programming (Table 3, case P4)

that assure that a joint load capacity of $7400 \mathrm{~N}$ is obtained with a standard deviation of the tensile/shear test results of $152.46 \mathrm{~N}$.

4. The correlation effect of the rotational speed of the tool and the duration of welding on the formation of a suitable temperature in the weld zone means that the selection of welding parameters must be preceded by multicriteria optimization. The method of solving the optimization problem with the use of goal programming presented in the article can be a very useful tool in the determination of the optimal parameters of the friction stir spot welding process. It ensures the determination of process parameters that ensure compliance with the requirements set by the constructor.

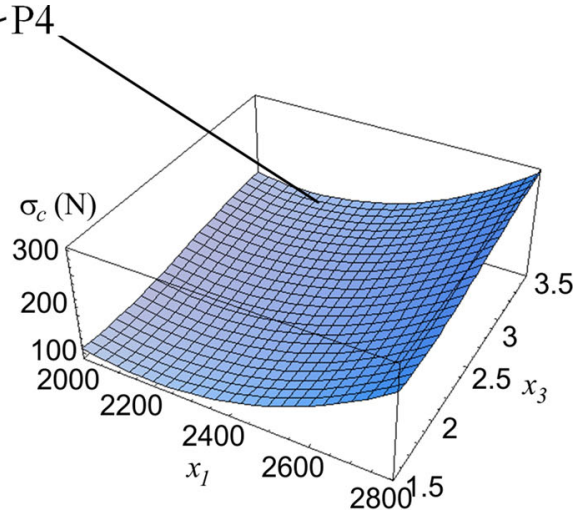

\section{Open Access}

This article is distributed under the terms of the Creative Commons Attribution 4.0 International License (http://creativeco mmons.org/licenses/by/4.0/), which permits unrestricted use, distribution, and reproduction in any medium, provided you give appropriate credit to the original author(s) and the source, provide a link to the Creative Commons license, and indicate if changes were made.

\section{References}

1. A. Barbini, J. Carstensen, and J.F. dos Santos, Influence of a Nonrotating Shoulder on Heat Generation, Microstructure and Mechanical 
Properties of Dissimilar AA2024/AA7050 FSW Joints, J. Mater Process. Technol., 2018, 34(1), p 119-127

2. Q. Chu, W.Y. Li, X.W. Yang, J.J. Shen, A. Vairis, W.Y. Feng, and W.B. Wang, Microstructure and Mechanical Optimization of Probeless Friction Stir Spot Welded Joint of An Al-Li Alloy, J. Mater. Process. Technol., 2018, 34(10), p 1739-1746

3. D. Burfordt, C. Widener, and B. Tweedy, Advances in FRICTION Stir Welding and Processing for Aerospace Applications, Airframer, 2006, 4, p 3-8

4. C. Schilling, J.F. dos Santos, Method and Device for Linking at Least Two Adjoining Work Pieces by Friction Welding. International Patent Publication WO/2001/036144, 2005

5. C. Oberembt, C. Allen, W. Arbegast, and A. Patnaik, Screening for Process Variable Sensitivity in Refill Friction Spot Welding of 6061 Aluminium Sheet, Friction Stir Welding and Processing IV, R.S. Mishra, M.W. Mahoney, T.J. Lienert, and K.V. Jata, Ed., Metals and Materials Society, USA, The Minerals, 2007, p 359-368

6. Z. Shen, Y. Chen, J.S.C. Hou, X. Yang, and A.P. Gerlich, Influence of Processing Parameters on Microstructure and Mechanical Performance of Refill Friction Stir Spot Welded 7075-T6 Aluminium Alloy, Sci. Technol. Weld. Joi., 2015, 20(1), p 48-57

7. R.N. Verastegui, J.A.E. Mazzaferro, C.C.P. Mazzaferro, T.R. Strohaecker, and J.F. dos Santos, Welding of Aluminum to DP600 Steel Plates by Refill Friction Stir Spot Welding Process (Refill FSSW), $A d v$. Mater. Res., 2015, 1082, p 123-132

8. Z. Li, S. Gao, S. Ji, Y. Yue, and P. Chai, Effect of Rotational Speed on Microstructure and Mechanical Properties of Refill Friction Stir Spot Welded 2024 Al Alloy, J. Mater. Eng. Perform., 2016, 25(4), p 1673-1682
9. M.A.D. Tier, T.S. Rosendo, J.F. dos Santos, N. Huber, J.A. Mazzaferro, C.P. Mazzaferro, and T.R. Strohaecker, The Influence of Refill FSSW Parameters on the Microstructure and Shear Strength of 5042 Aluminium Welds, J. Mater. Process. Technol., 2013, 213(6), p 997-1005

10. E.R. Dhas and J.H. Dhas, A Review on Optimization of Welding Process, Procedia Eng., 2012, 2012(38), p 544-554

11. L. Zhou, L.Y. Luo, R. Wang, J.B. Zhang, Y.X. Huang, and X.G. Song, Process Parameter Optimization in Refill Friction Spot Welding of 6061 Aluminum Alloys Using Response Surface Methodology, Mater. Eng. Perform., 2018, 27(8), p 4050-4058

12. Metallic materials-Tensile testing-Part 1: Method of test at room temperature, EN ISO 6892-1, International Organization for Standardization, 2016

13. Z. Li, S. Ji, Y. Ma, P. Chai, Y. Yue, and S. Gao, Fracture Mechanism of Refill Friction Stir Spot-Welded 2024-T4 Aluminum Alloy, Int. J. Adv. Manuf. Technol., 2016, 86(5-8), p 1925-1932

14. S. Venukumar, S. Yalagi, and S. Muthukumaran, Comparison of Microstructure and Mechanical Properties of Conventional and Refilled Friction Stir Spot Welds in AA 6061-T6 using Filler Plate, Trans. Nonferr. Metals Soc. China, 2013, 23(10), p 2833-2842

15. A. Kubit, R. Kluz, T. Trzepieciński, D. Wydrzyński, and W. Bochnowski, Analysis of the Mechanical Properties and of Micrographs of Refill Friction Stir Spot Welded 7075-T6 Aluminium Sheets, Arch. Civ. Mech. Eng., 2018, 18(1), p 235-244

Publisher's Note Springer Nature remains neutral with regard to jurisdictional claims in published maps and institutional affiliations. 